\title{
Measuring health-related quality of life for child maltreatment: a systematic literature review Lisa A Prosser ${ }^{1}$ and Phaedra S Corso*2
}

\author{
Address: ${ }^{1}$ Center for Child Health Care Studies, Harvard Medical School and Harvard Pilgrim Health Care, Department of Ambulatory Care and \\ Prevention, Boston, MA, USA and ${ }^{2}$ College of Public Health, University of Georgia, Athens, GA, USA \\ Email: Lisa A Prosser - lprosser@hms.harvard.edu; Phaedra S Corso* - pcorso@uga.edu \\ * Corresponding author \\ Published: 16 July 2007 \\ Health and Quality of Life Outcomes 2007, 5:42 doi:10.1 186/1477-7525-5-42 \\ This article is available from: http://www.hqlo.com/content/5///42 \\ This is an Open Access article distributed under the terms of the Creative Commons Attribution License (http://creativecommons.org/licenses/by/2.0), \\ which permits unrestricted use, distribution, and reproduction in any medium, provided the original work is properly cited.
}

\begin{abstract}
Background: Child maltreatment causes substantial morbidity and mortality in the U.S. Morbidity associated with child maltreatment can reduce health-related quality of life. Accurately measuring the reduction in quality of life associated with child maltreatment is essential to the economic evaluation of educational programs and interventions to reduce the incidence of child maltreatment. The objective of this study was to review the literature for existing approaches and instruments for measuring quality-oflife for child maltreatment outcomes.

Methods: We reviewed the current literature to identify current approaches to valuing child maltreatment outcomes for economic evaluations. We also reviewed available preference-based generic QOL instruments (EQ-5D, HUI, QWB, SF-6D) for appropriateness in measuring change in quality of life due to child maltreatment.

Results: We did not identify any studies that directly evaluated quality-of-life in maltreated children. We identified 4 studies that evaluated quality of life for adult survivors of child maltreatment and 8 studies that measured quality-of-life for pediatric injury not related to child maltreatment. No study reported qualityof-life values for children younger than age 3.

Currently available preference-based QOL instruments (EQ-5D, HUI, QWB, SF-6D) have been developed primarily for adults with the exception of the Health Utilities Index. These instruments do not include many of the domains identified as being important in capturing changes in quality of life for child maltreatment, such as potential for growth and development or psychological sequelae specific to maltreatment.

Conclusion: Recommendations for valuing preference-based quality-of-life for child maltreatment will vary by developmental level and type of maltreatment. In the short-term, available multi-attribute utility instruments should be considered in the context of the type of child maltreatment being measured. However, if relevant domains are not included in existing instruments or if valuing health for children less than 6 years of age, direct valuation with a proxy respondent is recommended. The choice of a proxy respondent is not clear in the case of child maltreatment since the parent may not be a suitable proxy. Adult survivors should be considered as appropriate proxies. Longer-term research should focus on identifying the key domains for measuring child health and the development of preference-based qualityof-life instruments that are appropriate for valuing child maltreatment outcomes.
\end{abstract}




\section{Background}

Child maltreatment, typically defined as physical abuse, sexual abuse, emotional abuse, physical neglect, and/or emotional neglect of children ages $0-17$ years by their parents or caretakers, causes substantial morbidity and mortality in the United States. The most recent report estimates that approximately 906,000 children were maltreated in the US in 2003, and an estimated 1,500 children were confirmed to have died from their injuries[1]. Estimates of the lifetime economic impact of child maltreatment, as measured by direct medical costs and productivity losses, have been estimated as $\$ 93$ billion[2]. Although large, these estimates likely represent an underestimate of the true burden of child maltreatment due to the lack of accurate incidence reporting and the inability to assess costs for indirect effects of child maltreatment on temporary or permanent physical and cognitive disabilities, and sustained losses in future education and occupational attainment[3]. Furthermore, there is evidence that child maltreatment can cause an increase in risky behaviors later in life such as smoking, alcoholism, drug use, eating disorders, obesity, depression, suicide, sexual promiscuity and specific chronic diseases [4-9]. Maltreatment that occurs during infancy or early childhood such as shaken-baby syndrome (SDS) can similarly lead to lifelong physical, mental and cognitive impairments because the brain has been damaged[10].

This broad range of child maltreatment's impact on health suggests that it may also have a substantial impact on its victims' life expectancy and long-term health-related quality of life (HRQL). HRQL can be measured using either health status measures or preference-based measures, with each category providing different information. Health status measures summarize the presence, absence, severity, frequency, and/or duration of specific symptoms, impairment, or disabilities. Examples of health status measures used in children include the Pediatric Quality of Life Inventory (Peds-QL), Child Health and Illness Profile (CHIP), and the Child Health Questionnaire (CHQ) $[11,12]$. These measures provide information on several domains of HRQL. In contrast, preference-based measures provide a summary value for a respondent's valuation of the quality of life of a particular health state, incorporating all positive and negative aspects of a health state into a single number. A commonly used approach for valuing preferences in health is utility. A utility value is typically scaled between 1.0, representing perfect health, and 0.0, representing a health state judged equivalent to being dead (although health states worse than dead can be scaled less than zero). Economic evaluations require the use of a preference-based measure of health states to correctly value changes in health [13-15].
Cost-effectiveness analysis, a type of economic evaluation, is one of the most widely used tools available to policy makers to measure the relative value of health care interventions. Cost-effectiveness analyses can be used by health insurers as well as federal and state policy makers as important guides to the allocation of resources. They provide the cost per health benefit gained from any single health intervention and also help to demonstrate which of two competing health care interventions is a better value[16]. Cost-utility analysis, a subset of cost-effectiveness analysis, uses a generic measure of benefit, the quality-adjusted life year (QALY), to measure the amount of health benefit associated with an intervention. The quality of a cost-utility analysis depends in large part on the quality of the inputs into the analysis as well as on the validity of the structure of the model. These inputs typically fall into three categories: probabilities, costs, and quality adjustments for health outcomes (to calculate QALYs gained). Therefore, the validity of a cost-effectiveness analysis will depend upon the appropriate valuation of health benefits.

In the context of child maltreatment, economic evaluation can be used to answer key questions, such as, are home visitation programs cost-effective relative to alternative interventions designed to reduce child maltreatment? Do these programs provide a positive return on investment, and from whose perspective? Are programs, that are provided in different settings, with different practitioners, to different target populations, delivered in a cost-efficient manner?

Scant research has focused on measuring HRQL for maltreated children; yet, to evaluate the total effectiveness of intervention/prevention programs for child maltreatment, accurate measures of the effect of child maltreatment on HRQL must be utilized that capture changes in all relevant domains of health. In addition, these measures need to appropriately capture the long-term impacts of child maltreatment that can occur in adulthood.

This study reviews the available literature on HRQL associated with child maltreatment using either preferencebased, health status, or other approaches. There are two general approaches to measuring preference-based quality of life for economic evaluations: direct assessment or multi-attribute utility instruments. We will consider advantages and disadvantages of each of these approaches for measuring HRQL for child maltreatment. We will also describe challenges specific to eliciting utilities from children such as cognitive challenges of the task, using parent as proxies, defining health differently than from adults, using community- level weights (or tariffs) that have been elicited from adult populations and applying them to 
child defined health states. Recommendations for next steps and future research are detailed.

\section{Methods}

\section{Literature search and study selection}

Literature searches were conducted to identify (1) studies that measured HRQL for child maltreatment outcomes and economic evaluations of child maltreatment prevention or intervention programs, and (2) existing multiattribute and health status instruments for children and adults. Three databases were utilized: PubMed, Econlit, and PsychInfo. Search terms and search strategies are listed in Appendix 1 [see Additional file 1].

\section{Study inclusion/exclusion}

The search for studies that measured HRQL for child maltreatment was limited to literature from English speaking countries and published between the years 1976-2006. At the first stage, article titles were reviewed and any articles that had HRQL, preferences and/or economic evaluation were included. In the next stage, abstracts were read to confirm that studies were relevant. A complete reading of the remaining articles was done to verify that all the papers contained the appropriate information. Articles were excluded at this stage, if subjects were greater than 17 years of age and/or did not meet the criteria listed above.

A data abstraction form (Appendix 2) [see Additional file 2] was specifically created to summarize all significant information from articles and to collect data in an organized fashion that would be simple to analyze. The abstraction form contained information on descriptive elements of the study, including: title of the article, authors' names, name of the journal and year it was published, country of origin, time frame, type of maltreatment, type of study (i.e. health status, preference-based, descriptive), how preferences were measured, and HRQL instruments utilized. The form assisted in the collection of specific methodologic information and categorized data elements into the following items: source of preferences (i.e. patient, parent, expert etc.), age of respondents, technique used in valuing preferences such as direct (i.e. rating scale, standard gamble, time trade off) and indirect (i.e. Health Utilities Index, Quality of Well-Being scale, EuroQol-5D) assessment of preferences, identification of the rater of health states in the study (i.e. patient, parent, and expert), age of rater, if the raters experienced health states and if so, how long were the health states and what were the health states, and age of the child whose HRQL was assessed.

The detailed information collected in the abstraction form allowed us to assess methods for calculating QALYs, observe which techniques and instruments were used to measure preferences as well as whose quality of life was assessed, and to identify from whom values were obtained.

The literature was then reviewed to identify generic quality of life instruments that could be applied to child maltreatment. The instruments reviewed were the Euroqol 5 dimension scale (EQ-5D)[17], the Health Utilities Index (HUI)[18], the Quality of Well Being scale (QWB)[19], and the Short Form 36 (SF-36)[20]. Pediatric HRQL instruments such as Pediatric Quality of Life Inventory (Peds-QL)[21], Functional Status II (FS II)[22], Health Status Questionnaire (HSQ)[23], Child Health Questionnaire (CHQ)[24], and Child Health and Illness Profile (CHIP-CE)[12] were also investigated to ascertain which domains were covered and if they were applicable to child maltreatment. The following information was collected: a description of the instrument, including domains and attribute levels of health, target population and target health outcome, a description of reliability and validity testing, and scoring system, if available.

\section{Results}

Literature review

The original search identified 1960 candidate articles from PubMed (91\%), PsychInfo (8\%), and EconLit (1\%). At the first stage, 1573 articles were eliminated because they did not meet the inclusion criteria and/or were duplicate papers. At abstract review, another 364 were eliminated because they did not include measures of HRQL related to child maltreatment. 23 papers were retrieved for full review and an additional 7 were eliminated as they did not include measures of HRQL related to child maltreatment. Due to the small number of papers, we also retained studies that measured HRQL for outcomes that might be related to child maltreatment (e.g., injury) and for adult survivors of child maltreatment.

All of the studies were published since 1990 and all except one were conducted in the United States. The CHQ and SF-36 were each used in 3 studies; "monetized QALYs" in 2 studies; the Vineland scale and Peds-QL were each used in one study; and other approaches used in 2 studies. Age of the subject's health being valued was 3 years or greater in all studies. Respondents had experienced the health state in half of the studies.

\section{Types of studies}

We did not identify any papers that directly measured HRQL for child maltreatment outcomes using standard gamble, time-tradeoff or rating scale methodologies. We identified 4 papers that indirectly measured HRQL for adult survivors of child maltreatment[3,25-27], 8 papers that measured HRQL for pediatric injury not specifically related to child maltreatment [25,28-33], and 4 papers that reported costs for hospitalizations or investigations 
related to suspected abuse [34-37]. Key data elements abstracted from these 12 papers are listed in Appendix 3 [see Additional file 3].

Of the studies that evaluated HRQL for adult survivors of child maltreatment, 3 used the SF-36 [25-27] and one developed their own survey that included questions on health status, leisure-time physical activity, depressed mood and suicide attempts from other validated questionnaires including the Conflicts Tactics Scale, the National Health Interview Survey, the Behavioral Risk Factor Surveillance Survey, and the National Health and Nutrition Examination Survey [3,38]. No study used a validated preference-based QOL instrument such as the EQ$5 \mathrm{D}, \mathrm{HUI}$, or QWB. While it is possible to derive utility scores from the SF-6D (a subset of questions from the SF36) using an algorithm developed by Brazier et al.[39], this approach was not utilized in any of the published studies.

Of the 8 studies that measured HRQL for pediatric injuries not specifically related to maltreatment, 3 used an approach consistent with preference-based measurement. One used the QWB and 2 used "monetized QALYs". In the 2 studies that used monetized QALYs, injuries were scored using the Functional Capacity Index and translated to a loss in QALYs using a combination of utility scores and rating scale estimates from 5 sources (HUI-1, QWB, jury awards, expert opinion, and student ratings). The number of QALYs lost was then multiplied by the willingness-topay for an additional QALY derived from estimates of the value for a statistical life[28,40,41]. One study used the QWB to report health status scores but did not use the QWB to calculate utility weights [25]. Three studies used the CHQ to measure HRQL for injury (all types) and traumatic brain injury $[30,31,33]$. One study used the PedsQL to value quality-of-life for traumatic brain injury [32]. One was a review of pediatric quality-of-life instruments that could be used to evaluate pediatric injury [29].

The 4 cost studies reported costs of hospitalizations for burns [35], pediatric intensive care admissions for child maltreatment [36], poison [34], and investigation of suspected abuse [37]. We also identified a benefit-cost analysis of a nurse home visitation program to improve child health outcomes, but this was conducted from the government perspective and included direct government costs only[42]. None of these studies included measures of HRQL and are not considered further in this review. Health domains relevant to child maltreatment were identified through the literature review and expert opinion (Table 1).

\section{Generic qualify of life instruments}

Five pediatric quality-of-life instruments (non-preferencebased) and six adult preference-based quality-of-life instruments were identified. Characteristics of pediatric quality-of-life instruments are detailed in Table 2. Domains of generic pediatric and adult quality-of-life instruments are listed in Table 3.

\section{Discussion}

This review underscores the scant attention that has been paid to measuring HRQL associated with child maltreatment outcomes. One reason for the paucity of data is likely due to challenges in accurately measuring preference-based quality-of-life in children including limits to the approaches typically used for valuing adult quality of life. Other potential reasons for the scarcity of data on this topic could include the difficulty in obtaining IRB approval for such a study, the morbid nature of the area and researchers' willingness to study this area. Preferencebased approaches for measuring the loss in health-related quality of life due to child maltreatment should be considered in the context of the general challenges of valuing preferences for children's health and additional challenges specific to child maltreatment.

\section{Challenges to valuing loss in HRQL for child maltreatment} A key challenge to valuing children's health for economic evaluations as compared to adults is the necessity of using a proxy respondent. Most children will need proxy respondents to complete value elicitation exercises. Prior studies have demonstrated that standard gamble and time trade-off surveys can only be reliably completed by children with at least a $6^{\text {th }}$ grade reading level [43] indicating that proxies will be required for most children 12 or younger. Adolescents may be able to value their own health, while school-age, preschool, and infants will require proxy respondents. Adolescents can complete such exercises but may demonstrate inconsistencies with using these valuation methods. When adolescents' values were compared to adult values for the same health states, adolescent values were significantly different than values elicited from parents or other adults[44,45]. An additional challenge for child maltreatment is that the parent/ caregiver may be the abuser and while the parent may be the natural proxy for valuing other types of children's health, the parent/caregiver will often not be the appropriate proxy. In the case of child maltreatment where the parent may be the abuser or may also be affected by abuse, an alternate proxy may be preferable. The optimal respondent may be adult survivors of maltreatment or adolescents affected by maltreatment. Using adult survivors may also be related to other biases such as recall bias or adjustment bias. If an adult survivor has overcome early child abuse or has many resulting health problems could potentially 
Table I: Health domains relevant to quality-of-life for child maltreatment.

\begin{tabular}{|c|c|c|}
\hline Category & Domains & Specific descriptions \\
\hline \multirow[t]{2}{*}{ Growth and development } & $\begin{array}{l}\text { Developmental progress/opportunity for } \\
\text { normal development }\end{array}$ & $\begin{array}{l}\text { Gross motor delays Fine motor delays Speech and language delays } \\
\text { Learning disabilities }\end{array}$ \\
\hline & $\begin{array}{l}\text { Communication and social interaction } \\
\text { through play }\end{array}$ & Communication Learning Social skills \\
\hline \multirow[t]{7}{*}{ Functioning } & Feeding & Feeding issues Malnutrition \\
\hline & Dressing & \\
\hline & Bathing & \\
\hline & Toilet constancy & Continence \\
\hline & Mobility & \\
\hline & Attending school & Ability to function in school Truancy \\
\hline & Interacting with peers & \\
\hline \multirow[t]{2}{*}{ Physical Health } & Routine medical care & Immunization delay Lack of well child care Dental caries \\
\hline & Physical Function & $\begin{array}{l}\text { Permanent or semipermanent Limb deformity, contractures Brain } \\
\text { injury (seizure disorders, visual impairment) }\end{array}$ \\
\hline \multirow{5}{*}{$\begin{array}{l}\text { Emotional Well-being/Mental } \\
\text { Health }\end{array}$} & Anxiety & Post-traumatic stress disorder \\
\hline & Depression & \\
\hline & Anger & \\
\hline & Risky behavior & $\begin{array}{l}\text { Promiscuity, teen pregnancy, sexually transmitted infections, juvenile } \\
\text { delinquency (incarceration), suicide, smoking, alcohol abuse, drug } \\
\text { abuse }\end{array}$ \\
\hline & Other psychiatric disorders & Obesity, eating disorders, body dysmorphic disorders, GI disorders \\
\hline \multirow[t]{3}{*}{ Placement and family stability } & Function within a family & Attachment disorders \\
\hline & Impact on parents/caregivers & \\
\hline & Foster care, adoption & \\
\hline
\end{tabular}

affect how one recalls and values the maltreatment experience.

The age of a child during the health state also poses methodological and practical challenges to valuing child health. For the same illness, the valuation of a health state may vary depending on the age of the affected person holding all other aspects of health constant. For example, maltreatment domains could vary between infants and adolescents as the most prevalent type of maltreatment tends to vary by age[46]. The long-term impacts of child maltreatment in adulthood should also be measured; several studies have demonstrated an impact on quality of life in adults[3,38,47]. This issue must be considered in the design or use of multi-attribute instruments.

None of the existing preference-based or pediatric QOL instruments address QOL for children under 2, and this age group poses significant challenges for measuring QOL. Some have advocated an approach that includes spillover effects on other family members [48], but such an approach may be inconsistent with valuing child maltreatment since the parent/caregiver may be the abuser. Thus, methods for valuing child maltreatment outcomes may depart from the development of general methods for valuing children's health.
There are additional challenges specific to measuring quality-of-life for child maltreatment (violence) that include difficulty in defining the severity of violence in a consistent way, changing pattern of maltreatment over time, and the potential exclusion of parent/caregiver as a candidate for proxy respondent. The increased prevalence of child maltreatment among children with disabilities [49] also presents additional problems in measuring QOL in already-disabled children.

\section{Strengths and limitations of existing approaches to valuing health}

Preferences for child maltreatment health states can be derived using one of the available multi-attribute utility instruments (EQ-5D, HUI, QWB) [17-19]. The most appropriate respondents using this approach would be adolescents or adult survivors valuing experienced health states. The EQ-5D has the most representative sample but does not include some key domains for valuing child health. The HUI and QWB include additional domains but utility weights are based on small and non-representative samples.

A number of instruments have been developed to measure quality of life in children but are not preference-based. One research option would be to develop utility weights 
for one or more of these instruments similar to the approach used for the SF-6D. The advantage of deriving utility weights for an existing instrument is that many of these instruments already include domains specific to child health and child maltreatment and have been validated for children. The Peds-QL also offers age-specific versions of its instrument for ages 2-7, 8-12, 13-16. Disadvantages of this approach are the lack of instruments for valuing infant health and that some domains specific to child maltreatment may be missing.

The direct valuation approach tends to be more resourceintensive than the use of a multi-attribute utility instrument but may produce more accurate measurements of quality of life associated with child maltreatment since the surveys can be designed to include all domains relevant to child maltreatment. Utilities could be elicited from adolescents or adult survivors valuing experienced health states or from a community sample valuing hypothetical health state descriptions of child maltreatment. Either "patient" or "community"-perspective utility weights can be elicited via direct valuation. Utilities for child maltreatment states of health can be directly assessed using either standard-gamble or time-tradeoff questions[13].

\section{Conclusion}

Neither currently available preference-based HRQL instruments nor direct valuation approaches provide ready solutions for measuring preference-based quality of life in child maltreatment. Currently available preferencebased HRQL instruments were developed primarily for chronic conditions in adults and may not fully capture loss in quality of life associated with domains of health relevant to child maltreatment or complex health states that include both temporary and chronic health events. Nevertheless, these instruments represent a good shortterm solution. Direct valuation approaches present a number of methodologic and practical challenges when applied to pediatric populations but can be designed to better capture loss in quality of life compared to existing HRQL instruments.

For both approaches, the challenges of eliciting values will differ according to age groups: infant, preschool, schoolage, and adolescent. In addition, direct valuation can be more expensive and time-consuming. It can also be more difficult logistically to obtain values from a representative national sample when using direct valuation.

This review did not originally focus on measuring quality of life for adult survivors of maltreatment but articles identified in the literature search were reviewed given the scarcity of literature on quality of life and child maltreatment at the time of maltreatment. Nor did we consider how psychological abuse in childhood could manifest as physical outcomes in adults. We also did not specifically include the effects of witnessing domestic violence, although consequences of witnessing domestic violence on physical and psychological outcomes could also be substantial.

In the short term, preference-based HRQL for child maltreatment from the community perspective can be most easily measured using the EQ-5D (or another preferencebased HRQL instruments) with either adult survivors and/ or adolescents who have experienced maltreatment. The sample used to derive utility weights for the EQ-5D is the most representative sample of the available preferencebased QOL instruments for US policy decisions[50]. In addition, the EQ-5D covers at least 2 of the domains that are likely to be directly relevant to child maltreatment: physical functioning and emotional well-being. However, this approach will not be able to provide any quality-oflife effects specific to children (e.g., growth and development) and does not provide values for "experienced" utility.

If the objective is to measure experienced utilities (i.e., the "patient perspective"), this could be achieved using direct valuation measures with adult survivors or adolescents rating their own childhood experience. While adolescents who have experienced child maltreatment may be the most suitable proxy since they have direct experience with the health state and recall bias will be less than for older adult survivors since less time has passed since the experience, adolescents' responses may be biased as described above. In addition, respondent burden must be considered. If it is too emotionally burdensome for adolescents to answer these types of questions, other respondents must be considered.

A third alternative is to have a community sample rate hypothetical descriptions of child maltreatment. This would provide community weights that might better reflect quality of life associated with child maltreatment but will be more resource-intensive compared to using an existing preference-based HRQL instrument.

Longer-term research should focus on identifying the key domains for measuring child health. Identifying the domains that are most relevant to child maltreatment will allow for a more comprehensive evaluation of existing preference-based and pediatric HRQL instruments. Consideration should be given to how the different types of child maltreatment affect different domains of quality of life.

The conclusion of this review is that the existing pediatric HRQL instruments cover a more comprehensive set of domains relevant to children's health and specifically 
Table 2: Characteristics of pediatric quality-of-life instruments.

\begin{tabular}{|c|c|c|c|c|c|c|}
\hline Instrument & Domains & $\begin{array}{l}\text { Number of } \\
\text { Items }\end{array}$ & $\begin{array}{l}\text { Time to } \\
\text { complete } \\
\text { (approximate) }\end{array}$ & $\begin{array}{l}\text { Ages Intended } \\
\text { For }\end{array}$ & Respondent & $\begin{array}{l}\text { Year } \\
\text { Developed }\end{array}$ \\
\hline Peds-OL & $\begin{array}{l}3 \text { Domains } \\
\text {-Physical Functioning } \\
\text {-Psychological Functioning } \\
\text {-Social Functioning }\end{array}$ & 15 items & $5-10$ minutes & $\begin{array}{l}2-7 \text { years } \\
8-12 \text { years } \\
13-16 \text { years }\end{array}$ & $\begin{array}{l}\text { Parent/proxy } \\
\text { Child }\end{array}$ & 1998 \\
\hline FS II & $\begin{array}{l}8 \text { Domains } \\
\text {-Communication } \\
\text {-Mobility } \\
\text {-Mood } \\
\text {-Energy } \\
\text {-Play } \\
\text {-Sleep } \\
\text {-Eating } \\
\text {-Toilet patterns }\end{array}$ & $\begin{array}{l}43 \text { items (long } \\
\text { version) } \\
\text { I } 4 \text { items (short } \\
\text { version) }\end{array}$ & 30 minutes & $0-16$ years & Parent & 1978 \\
\hline CHSQ & $\begin{array}{l}5 \text { Domains } \\
\text {-Physical Health } \\
\text {-Mental Health } \\
\text {-Social Relations } \\
\text {-General Health } \\
\text {-Satisfaction with } \\
\text { development }\end{array}$ & 34 items & $10-15$ minutes & 2 year + & $\begin{array}{l}\text { Pediatrician form } \\
\text { Parental form }\end{array}$ & 1994 \\
\hline $\mathrm{CHQ}$ & $\begin{array}{l}\text { I4 Domains } \\
\text {-Physical Functioning } \\
\text {-Social Functioning } \\
\text {-Bodily/Discomfort } \\
\text {-General Behavior } \\
\text {-Mental Health } \\
\text {-General Health } \\
\text { Perception } \\
\text {-Self Esteem } \\
\text {-Parental Impact (time \& } \\
\text { emotional) } \\
\text {-Family Functioning } \\
\text { (actives \& cohesion) }\end{array}$ & & 20 minutes & $\begin{array}{l}5-13 \text { years } \\
10-18 \text { years }\end{array}$ & $\begin{array}{l}\text { Parent/Proxy (CHQ-PF- } \\
\text { 98; PF-50; PF-28) } \\
\text { Children (CHQ-CF-87) } \\
\text { No parallel versions }\end{array}$ & $\begin{array}{l}1990 \\
1994-1995\end{array}$ \\
\hline CHIP & $\begin{array}{l}7 \text { Domains } \\
\text {-20 sub domains } \\
\text {-Satisfaction } \\
\text {-Comfort } \\
\text {-Resilience } \\
\text {-Risk Avoidance } \\
\text {-Achievement } \\
\text {-Disorders } \\
\text {-Home Safety \& Health }\end{array}$ & $\begin{array}{l}\text { I07 items } 46 \\
\text { specific to disease } \\
\text { or injury }\end{array}$ & 30 minutes & $\begin{array}{l}6-11 \text { years }(C E) \\
11-18 \text { years } \\
(A E)\end{array}$ & Parent/Proxy Child & 1993 \\
\hline
\end{tabular}

child maltreatment than the preference-based generic HRQL instruments. If this finding is confirmed, then the recommended approach would be to either (1) develop utility weights for one of the pediatric quality of life instruments or (2) design a new preference-based HRQL instrument to measure preferences for child health/maltreatment. The Peds-QL covers relevant domains and offers age-specific versions and could be a good candidate for the first approach. Any approach needs to consider the special characteristics of valuing child health. If children are to complete surveys themselves, the use of age-appropriate visual aids that improve reliability and validity of responses will be essential[51]. Long-term effects of child maltreatment should also be considered. Although maltreatment may occur during childhood, many of the negative consequences will affect a maltreated individual throughout the lifecourse, and this should be considered when developing appropriate measures. If an instrument were developed specifically for measuring effects of child maltreatment, then the optimal approach may be to develop an instrument that can measure HRQL related to child maltreatment for all ages, child to adult. Additional research is needed to improve methods for measuring preference-based quality of life in child maltreatment. 
Table 3: Domains included in multi-attribute utility and pediatric quality-of-life instruments.

\begin{tabular}{|c|c|c|c|c|c|c|c|c|c|c|c|c|}
\hline \multirow[b]{2}{*}{ Domains Covered } & \multicolumn{6}{|c|}{ Generic QOL instruments with utility weights } & \multicolumn{5}{|c|}{ Pediatric QOL instruments } & \multirow{2}{*}{$\begin{array}{c}\begin{array}{c}\text { Relevant to } \\
\text { maltreatment }\end{array} \\
\begin{array}{c}\text { Domains } \\
\text { specific to } \\
\text { child }\end{array} \\
\text { maltreatment }\end{array}$} \\
\hline & EQ-5D & HUI 2 & HUI 3 & QWB & SF-36 & SF-6D & PedsQL & FS II & CHSQ & CHQ & CHIP & \\
\hline $\begin{array}{l}\text { Physical Functioning/ } \\
\text { Physical Health }\end{array}$ & $x$ & $x$ & $x$ & $x$ & $x$ & $x$ & $x$ & $x$ & $x$ & $x$ & $x$ & $x$ \\
\hline Mobility & - & - & - & - & - & - & - & $x$ & $x$ & & $x$ & $\mathrm{x}$ \\
\hline Pain/Discomfort & $\mathrm{x}$ & - & $\mathrm{x}$ & - & $x$ & $x$ & $x$ & - & - & $x$ & $x$ & $x$ \\
\hline Self Care & - & $x$ & - & - & - & - & $x$ & - & - & - & - & - \\
\hline Sleep/Rest & - & - & - & - & - & - & $x$ & $x$ & - & - & - & - \\
\hline Energy/Vitality & - & - & - & - & - & $x$ & $x$ & $x$ & - & - & - & - \\
\hline Toilet patterns & - & - & - & - & - & - & - & $x$ & - & - & - & $x$ \\
\hline $\begin{array}{l}\text { Cognitive } \\
\text { Functioning }\end{array}$ & - & $x$ & $x$ & - & - & - & $x$ & - & - & - & - & - \\
\hline $\begin{array}{l}\text { Symptoms } \\
\text { (impairments) }\end{array}$ & - & $x$ & $x$ & $x$ & - & - & - & - & $x$ & - & - & - \\
\hline $\begin{array}{l}\text { Sensory function } \\
\text { (loss) }\end{array}$ & - & $x$ & $x$ & - & - & - & & & $x$ & - & - & $x$ \\
\hline Respiratory Function & - & - & - & - & - & - & - & - & $x$ & - & - & $x$ \\
\hline Renal Function & - & - & - & - & - & - & - & - & $x$ & - & - & - \\
\hline $\begin{array}{l}\text { Perceptions in } \\
\text { Health }\end{array}$ & - & - & - & - & $x$ & - & - & - & - & - & $x$ & $x$ \\
\hline Social Functioning & - & $x$ & - & $x$ & $x$ & $x$ & $x$ & $x$ & - & $x$ & $x$ & $x$ \\
\hline $\begin{array}{l}\text { Other: Recreation/ } \\
\text { Past Times/Activity }\end{array}$ & $x$ & - & - & - & $x$ & - & $x$ & $x$ & - & $x$ & - & $x$ \\
\hline Work/School & - & - & - & - & $x$ & $x$ & $x$ & $x$ & - & $x$ & $x$ & $x$ \\
\hline Home Management & - & - & - & - & $x$ & - & - & $x$ & - & - & - & - \\
\hline Eating & - & - & - & - & - & - & - & $x$ & $x$ & - & - & $x$ \\
\hline $\begin{array}{l}\text { Level of } \\
\text { Independence }\end{array}$ & $x$ & - & - & - & - & - & - & - & - & - & - & - \\
\hline Relationship & - & - & - & $x$ & - & - & - & - & - & $x$ & $x$ & $x$ \\
\hline Interactions & - & - & - & - & - & - & $x$ & - & - & $x$ & $x$ & $x$ \\
\hline $\begin{array}{l}\text { Emotional } \\
\text { Functioning/Metal } \\
\text { Health/Well Being }\end{array}$ & $x$ & $x$ & $x$ & $x$ & $x$ & $x$ & $x$ & - & - & $x$ & $x$ & $x$ \\
\hline $\begin{array}{l}\text { Other: Self-Image/ } \\
\text { Self Esteem }\end{array}$ & - & - & - & - & - & - & $x$ & - & - & $x$ & - & $x$ \\
\hline Behavior & - & - & - & - & - & - & - & - & - & $x$ & $x$ & $x$ \\
\hline $\begin{array}{l}\text { Distress/Health- } \\
\text { Related Distress }\end{array}$ & - & - & - & - & - & - & $x$ & - & - & - & $x$ & - \\
\hline $\begin{array}{l}\text { Life Satisfaction/ } \\
\text { Overall QoL }\end{array}$ & $x$ & - & - & - & - & - & - & - & - & - & $x$ & - \\
\hline Communication & - & $x$ & $x$ & - & - & - & $x$ & $x$ & $x$ & $x$ & - & - \\
\hline Parental Impact & - & - & - & - & - & - & - & - & - & $x$ & $x$ & - \\
\hline Family Activities & - & - & - & - & - & - & - & - & - & $x$ & $x$ & - \\
\hline $\begin{array}{l}\text { Family Function/ } \\
\text { Dynamics }\end{array}$ & - & - & - & - & - & - & - & - & - & $x$ & $x$ & $x$ \\
\hline $\begin{array}{l}\text { Overall Growth \& } \\
\text { Development }\end{array}$ & - & - & - & - & - & - & - & - & $x$ & $x$ & - & $x$ \\
\hline $\begin{array}{l}\text { Achievement- } \\
\text { Academically \& } \\
\text { Socially }\end{array}$ & - & - & - & - & - & - & $x$ & - & - & - & $x$ & $x$ \\
\hline $\begin{array}{l}\text { Home Safety \& } \\
\text { Health }\end{array}$ & - & - & - & - & - & - & - & - & - & - & $x$ & $x$ \\
\hline
\end{tabular}




\section{Competing interests}

The author(s) declare that they have no competing interests.

\section{Authors' contributions}

LP led the design and literature search, designed the abstraction forms, supervised data abstraction, performed the analysis, and drafted the manuscript. PC conceived of the study, participated in its design and interpretation of results, and participated in drafting the manuscript. All authors read and approved the final manuscript.

\section{Additional material}

\section{Additional file 1}

Appendix 1: Search terms for child maltreatment literature review Click here for file

[http://www.biomedcentral.com/content/supplementary/14777525-5-42-S1.doc]

\section{Additional file 2}

Appendix 2: Child Maltreatment - Data Extraction Form Click here for file

[http://www.biomedcentral.com/content/supplementary/14777525-5-42-S2.pdf]

\section{Additional file 3}

Appendix 3: Data abstracted from literature review

Click here for file

[http://www.biomedcentral.com/content/supplementary/14777525-5-42-S3.xls]

\section{Acknowledgements}

We would like to acknowledge the helpful comments of Bill Rhoads and Xiangming Fang, throughout the course of the project and development of this report. We would also like to thank the child maltreatment experts, Cindy Christian and Toni Laskey, who agreed to review a draft of the report and provided key feedback on domains of quality of life relevant to child maltreatment throughout the lifecourse. We also appreciate the expert administrative assistance provided by Andra Barnette and Christina Kara and research assistance provided by Robert Ravenscroft.

Funding was provided by the National Center for Injury Prevention and Control, Centers for Disease Control and Prevention (CDC). However, the views expressed within this article are those of the authors and do not necessarily represent the views of the $C D C$.

\section{References}

I. Child maltreatment 2003 [http://www.acf.hhs.gov/programs/cb/ pubs/cm03/index.htm].

2. Total estimated cost of child abuse and neglect in the United States - statistical evidence [http://member.preventchilda buse.org/site/DocServer/cost analysis.pdf?doclD=|44]

3. Felitti VJ, Anda RF, Nordenberg D, Williamson DF, Spitz AM, Edwards $V$, Koss MP, Marks JS: Relationship of childhood abuse and household dysfunction to many of the leading causes of death in adults. The Adverse Childhood Experiences (ACE) Study. Am J Prev Med 1998, 14:245-258.
4. Child abuse and neglect by parents and caregivers [http:// www.who.int/violence injury prevention/violence/global campaign/ en/chap3.pdf]

5. Kolko DJ: Child physical abuse. In The APSAC Handbook on Child Maltreatment 2nd edition. Edited by: Myers JEB, Berliner L, Briere J, Hendrix CT, Reid TA, Jenny CA. Thousands Oaks, CA: Sage Publications, Inc; 2002.

6. Kendall-Tackett K: Treating the lifetime health effects of childhood victimization Kingston, NJ: Civic Research Institute Inc; 2003.

7. Malinosky-Rummel R, Hansen DJ: Long-term consequences of childhood physical abuse. Psychol Bull 1995, I I 4:68-79.

8. Putnam FW: Ten-year research update review: child sexual abuse. J Am Acad Child Adolesc Psychiatry 2003, 42:269-278.

9. Paolucci EO, Genuis MG, Violato C: A meta-analysis of the published research on the effects of child sexual abuse. J Psychol 200I, 135:17-36.

10. National Research Council and Institute of Medicine: From Neurons to Neighborhoods: The Science of Early Childhood Development Washington, DC: National Academy Press; 2000.

II. Varni JW, Seid M, Rode CA: The PedsQL: measurement model for the pediatric quality of life inventory. Med Care 1999, 37:126-139.

12. Riley AW, Forrest CB, Rebok GW, Starfield B, Green BF, Robertson JA, Friello $P$ : The child report form of the CHIP-child edition: reliability and validity. Med Care 2004, 42:22I-23I.

13. Bennett KJ, Torrance GW: Measuring health state preferences and utilities: rating scale, time trade-off, and standard gamble techniques. In Quality of Life and Pharmacoeconomics in Clinical Trials 2nd edition. Edited by: Spilker B. Philadelphia: Lippincott-Raven; 1996:253-265.

14. Russell LB, Gold MR, Siegel JE, Daniels N, Weinstein MC: The role of cost-effectiveness analysis in health and medicine. JAMA 1996, 276: II72-1I77.

15. Neumann PJ, Goldie SJ, Weinstein MC: Preference-based measures in economic evaluation in health care. Annu Rev Pub Health 2000, $21: 1-25$.

16. Gold MR, Siegel JE, Russell LB, Weinstein MC, Eds: Cost-effectiveness in health and medicine New York: Oxford University Press; 1996.

17. Shaw JW, Johnson JA, Coons SJ: US valuation of the EQ-5D health states: development and testing of the DI valuation model. Med Care 2005, 43:203-220.

18. Furlong W], Feeny DH, Torrance GW, Barr RD: The Health Utilities Index (HUI) system for assessing health-related quality of life in clinical studies. Ann Med 2001, 33:375-384.

19. Sieber WJ, Groessl EJ, David KM, Ganiats TG, Kaplan RM: Quality of Well-Being Scale - Self-Administered (QWB-SA) San Diego; 2004.

20. Jenkinson $C$, Wright $L$, Coulter $A$ : Criterion validity and reliability of the SF-36 in a population sample. Qual Life Res 1994, 3:7-12.

21. Varni JW, Seid M: PedsQL 4.0 : reliability and validity of the Pediatric Quality of Life Inventory Version 4.0 Generic Core Scales in healthy and patient populations. Med Care 200I, 39:800-8I2.

22. Stein RE, Jessop DJ: Functional Status II(R): a measure of child health status. Med Care 1990, 28:104I-1055.

23. Jones HP, Guildea ZE, Steward JH, Cartlidge PH: The Health Status Questionnaire: achieving concordance with published disability criteria. Arch Dis Child 2002, 86:15-20.

24. Raat H, Bottweweck AM, Landgraf JM, Hoogeveen WC, Essink-Bot ML: Reliability and validity of the short form of child health questionnaire for parents (CHQ-PF28) in large random school based and general population samples. J Epidemiol Community Health 2005, 59:75-82.

25. Holbrook TL, Hoyt DB, Coimbra R, Potenza B, Sise M, Anderson JP: High rates of acute stress disorder impact quality of life outcomes in injured adolescents: mechanism and gender predict acute stress disorder risk. J Trauma 2005, 59: I I 26- I I 30.

26. Walker EA, Gelfand A, Katon WJ, Koss MP, Von Korff M, Bernstein $D$, Russo J: Adult health status of women with histories of childhood abuse and neglect. Am J Med 1999, 107:332-339.

27. Dickinson LM, de Gruy FV3, Dickinson WP, Candib LM: Healthrelated quality of life and symptoms profiles of female survivors of sexual abuse. Arch Fam Med 1999, 8:35-43.

28. Danseco ER, Miller TR, Spicer RS: Incidence and costs of 19871994 childhood injuries: demographic breakdowns. Pediatrics 2000, 105:E27. 
29. Hack M: Consideration of the use of health status, functional outcomes and quality-of-life to monitor neonatal intensive care practice. Pediatrics 1999, I 03:319-328.

30. Aitken ME, Tilford JM, Barrett KW, Parker JG, Simpson P, Landgraf J, Robbins JM: Health status of children after admission for injury. Pediatrics 2002, I l 0:337-342.

31. Stancin T, Drotar D, Taylor HG, Yeates KO, Wade SL, Minich NM: Health-related quality of life of children and adolescents after traumatic brain injury. Pediatrics 2002, I09:E34.

32. McCarthy ML, MacKenzie EJ, Durbin DR, Aitken ME, Jaffe KM, Paidas CN, Slomine BS, Dorsch AM, Berk RA, Christensen JR, et al.: The Pediatric Quality of Life Inventory: an evaluation of its reliability and validity for children with traumatic brain injury. Arch Phys Med Rehabil 2005, 86:1901-1909.

33. Davey TM, Aitken LM, Kassulke D, Bellamy N, Ambrose J, Gee T, Clark M: Long-term outcomes of seriously injured children: a study using the Child Health Questionnaire. J Paediatr Child Health 2005, 4I:278-283.

34. Woolf A, Wieler J, Greenes D: Costs of poison-related hospitalizations at an urban teaching hospital for children. Arch Pediatr Adolesc Med 1997, I 5 1:719-723.

35. Evasovich M, Klein R, Muakkassa F, Weekley R: The economic effect of child abuse in the burn unit. Burns 1998, 24:642-645.

36. Irazuzta JE, McJunkin JE, Danadian K, Arnold F, Zhang J: Outcome and cost of child abuse. Child Abuse Negl 1997, 21:751-757.

37. Summers CL, Molyneux EM: Suspected child abuse: cost in medical time and finance. Arch Dis Child 1992, 67:905-908.

38. Edwards VJ, Anda RF, Felitti VJ, Dube SR: Adverse childhood experiences and health-related quality of life as an adult. In Victimization and Health Edited by: Kendall-Tackett K. American Psychological Association; 2003.

39. Brazier J, Roberts J, Deverill M: The estimation of a preferencebased measure of health from the SF-36. J Health Econ 2002 2I:27I-292.

40. Winston FK, Weiss HB, Nance ML, Vivarelli-O'Neil C, Strotmeyer S, Lawrence BA, Miller TR: Estimates of the incidence and cost associated with handlebar-related injuries in children. Arch Pediatr Adolesc Med 2002, I 56:922-928.

41. Miller TR, Pindus NM, Douglass JB, Rossman SB: Databook on non-fatal injury: incidence, costs, and consequences 1995.

42. Olds DL, Henderson CRJ, Phelps C, Kitzman H, Hanks C: Effect of prenatal and infancy nurse home visitation on government spending. Med Care 1993, 3 I:I55-174.

43. Juniper EF, Guyatt GH, Feeny DH, Griffith LE, Ferrie PJ: Minimum skills required by children to complete health-related quality of life instruments for asthma: comparison of measurement properties. Eur Respir J 1997, 10:2285-2294.

44. Saigal S, Stoskopf BL, Feeny D, Furlong W, Burrows E, Rosenbaum PL Hoult L: Differences in preferences for neonatal outcomes amoung health care professionals, parents, and adolescents. JAMA 1999, 28I:|99|-1997.

45. Saigal S, Rosenbaum PL, Feeny D, Burrows E, Furlong W, Stoskopf BL, Hoult L: Parental perspectives of the health status and healthrelated quality of life of teen-aged children who were extremely low birth weight and term controls. Pediatrics 2000 , 1 05:569-574.

46. Theodore AD, Chang JJ, Runyan DK, Hunter WM, Bangdiwala SI, Agans R: Epidemiologic features of the physical and sexual maltreatment of children in the Carolinas. Pediatrics 2005, I I 5:e33I-e337.

47. Edwards VJ, Holden GW, Felitti VJ, Anda RF: Relationship between multiple forms of childhood maltreatment and adult mental health in community respondents: results from the adverse childhood experiences study. Am J Psychiatry 2003, 160: |453-1460.

48. Basu A, Meltzer D: Implications of spillover effects within the family for medical cost-effectiveness analysis. J Health Econ 2005, 24:75 I-773.

49. English DJ: The extent and consequences of child maltreatment. Future Child 1998, 8:39-53.

50. IOM Board on Health Care Services Committee to Evaluate Measures of Health Benefits for Environmental HaSR: Valuing health for regulatory cost-effectiveness analysis Washington, D.C; 2006.

51. Matza LS, Swensen AR, Flood EM, Secnik K, Leidy NK: Assessment of health-related quality of life in children: a review of con- ceptual, methodological, and regulatory issues. Value Health 2004, 7:79-92.
Publish with Biomed Central and every scientist can read your work free of charge

"BioMed Central will be the most significant development for disseminating the results of biomedical research in our lifetime. "

Sir Paul Nurse, Cancer Research UK

Your research papers will be:

- available free of charge to the entire biomedical community

- peer reviewed and published immediately upon acceptance

- cited in PubMed and archived on PubMed Central

- yours - you keep the copyright 